\title{
Pasión por vivir, pasión por crear. La poesía de Ana María Fagundo: una estética singular
}

\author{
Passion for Living, Passion for Creating. The Poetry of Ana María Fagundo: A \\ Singular Aesthetic
}

\author{
Blas Sánchez Dueñas \\ lh2sadub@uco.es \\ Universidad de Córdoba, España
}

Recepción: 12 Agosto 2019

Aprobación: 10 Mayo 2020

Publicación: 02 Noviembre 2020

Cita sugerida: Sánchez Dueñas, B. (2020). 'Pasión por vivir, pasión por crear. La poesía de Ana María Fagundo: una estética singular. Olivar, 20(32), e084. https://doi.org/10.24215/18524478e084
Resumen: Ana María Fagundo fue una poeta independiente y singular que hizo de la literatura un espacio propio desde el que indagar en pos del conocimiento y desde el que forjar un proyecto vital exclusivo como persona y como creadora. Desde la composición de su primer libro, la poesía pasó a convertirse en parte indisoluble de su ser y de su estar en el mundo hasta llegar a configurar un paisanaje literario propio vertebrado sobre dos claves esenciales: la creación como ámbito autóctono desde el que conformar vidas a través de la palabra y la defensa y afirmación de la vida frente al vacío y la incomunicación de las sociedades postmodernas. La presente investigación se centra en el análisis de estos dos aspectos por considerase como principios indispensables de su concepción poética y en abrir nuevas propuestas discursivas con respecto a otras particularidades de su obra con especial atención a su libro Desde Chanatel, el canto, al reunirse en él algunos de los motivos medulares de su particular universo lírico.

Palabras clave: Ana María Fagundo, Poética, Creación, Vida y obra.

Abstract: Ana María Fagundo was an independent and singular poet who made literature and poetry her own vehicles through which to explore, in pursuit of knowledge, and to forge an exclusive life project as a person and as a creator. With the composition of her first book, poetry became an indivisible part of her approach to inhabiting and dealing with the world, evolving into a literary landscape all her own, resting on two cornerstones: creation as an autochthonous sphere through which to shape lives, through words; and a defence and affirmation of life against the emptiness and isolation of postmodern societies. This study focuses on the analysis of these two aspects, which are considered indispensable principles of her poetic conception; and on suggesting new discursive perspectives on other particularities of her work, with particular stress on her book From Chanatel, The Song, as it contains some of the core theme of her particular lyrical universe.

Keywords: Ana María Fagundo, Poetics, Creation, Life and work. 


\section{Ana María Fagundo: una trayectoria poÉtica en TRES tiempos}

En doce volúmenes se agrupa la producción literaria de creación de Ana María Fagundo (Sta. Cruz de Tenerife, 1938 - Madrid, 2010) publicados en una línea temporal comprendida entre 1965, fecha de salida de Brotes (La Laguna, Tenerife: Maype), y 2008 fecha de edición de Materia en olvido (Santa Cruz de Tenerife: Idea). A ellos se suman una novela, La miríada de los sonámbulos (1994), tres libros de ensayo: Vida y obra de Emily Dickinson (1973), Antología bilingüe de poesía norteamericana contemporánea: 1950-1980 (1988) y Literatura femenina de España y las Américas (1995) así como un buen número de artículos de crítica e investigación centrados esencialmente en el área de la literatura española de posguerra.

Mención aparte merece la labor realizada en la dirección de los treinta y tres números de la revista Alaluz: revista de poesía, narración y ensayo, comandada por ella desde 1969 hasta su jubilación en 2001. Editada por la Universidad de Riverside (California), en la que Fagundo fue profesora de Literatura española desde 1967, y con una salida bianual (primavera y otoño), Alaluz es una revista esencial del contexto literario del último cuarto de siglo por su eclecticismo y cuidados editoriales así como por su pluralidad e interés al acoger en sus páginas tanto a escritores consagrados como a noveles y a poetas de diferentes tendencias, nacionalidades e ideologías desde Concha Zardoya a José Emilio Pacheco, pasando por Rafael Soto Vergués, Ernesto Cardenal, Luisa Pasamanik, Pablo Antonio Cuadra, Odiseas Elitis, Pura Vázquez, Alfonso Canales, Isabel Paraíso, Jorge Guillén, Cristina Peri Rossi, Fernando Alegría o Emilio Carilla, entre otros.

Ana María Fagundo Guerra fue una escritora independiente y periférica con respecto a los circuitos literarios dogmáticos y a las propuestas estéticas hegemónicas. Con mayor rigor que muchos otros poetas calificados como heterodoxos, A. Ma . Fagundo debe ser considerada como una poeta-isla, una poeta singular e insular al coadyuvar en torno a su genealogía personal y creadora diversas circunstancias que así lo deslindan: algunas de índole biográfica y extraliteraria y otras relacionadas con las diferentes ópticas que convergen y se refractan desde sus peculiares planteamientos doctrinales.

Aunque en su obra se explicitan líneas de horizontes y connotaciones similares a lo largo del tiempo y subyacen símbolos, constantes y referentes plenamente discernibles hasta el punto de llegar a configurar una obra unitaria y orgánica, su trayectoria poética podría estructurarse en tres tiempos según ha argumentado Silvia Rolle-Rissetto (1999, p. 8).

El despertar de su vocación literaria se estimula al compás de sus inquietudes cognoscitivas en franca ensambladura con poéticas de miembros de la poesía del medio siglo como José Ángel Valente o Enrique Badosa, autor de un opúsculo esencial titulado "Primero hablemos de Júpiter. La poesía como medio de conocimiento" (1959) y de poetas como Dylan Thomas para quien un buen poema, además de ayudar a cambiar la forma y el significado del universo, contribuye a extender el conocimiento de sí mismo y del mundo que le rodea.

Ana María Fagundo comienza a escribir para encontrar respuestas a las dudas que la asaltan y tratar de comprender todo aquello que un juvenil intelecto no alcanza a descifrar. Su primera etapa podría denominarse como fase de cuestionamiento e indagación cognoscitiva. Sus primeros libros giran sobre núcleos compositivos centrados en el proceso de génesis, de descubrimiento, de impulso y de indagación en torno a la propia creación literaria y al ser creador a la vez que se sumergen en tres esferas que, más tarde, atravesarán su obra futura, en muchos casos fundidos en una ósmosis orgánica: la búsqueda de la identidad y de la concepción del mundo por la palabra como elemento capital de aprehensión y proyección del pensamiento; la isla como espacio físico abierto e inabarcable desde donde se proyectan miradas e impresiones simbólicas hacia el pasado, el presente y el futuro fundidas con frecuencia con la propia personalidad de la escritora; y, en tercer lugar, la rememoración del pasado y el latente poso de la muerte y del paso del tiempo como vivencias o experiencias materiales concretas que duelen y que deben ser derrotadas que alcanzan una dimensión singular en la elegía Diario de una muerte, ejemplo de doloroso dietario particular confeccionado sobre el lento y 
doloroso proceso de enfermedad, muerte y ausencia de su padre. Los tres primeros libros de Fagundo serían los representativos de esta primera etapa: Brotes (1965), Isla adentro (1969), Diario de una muerte (1970).

El segundo momento de su ciclo poético se podría designar como fase de alumbramiento y desvelamiento de la creación autóctona. Este representa el punto culminante de una poética personal fuera de escuelas o de corrientes. Desde las propuestas iniciales, la poeta encuentra los cauces de su voz autóctona, diferenciada y singular. Se adentra en una poética configurada sobre los soportes de su identidad y corporeidad de mujer envueltos en torno al alumbramiento de una cosmogonía ginocéntrica y feminista donde el ser femenino se configura como figura central protagonista tanto en su inmanencia intrínseca femenina corporal e ideológica como en su proyección exterior en relación con el contexto, la naturaleza y la sociedad que la rodea. La poeta genera sus propios correlatos poéticos y su particular universo literario fundamentado sobre temas como la luz, el canto, el cuerpo femenino gestante, el gozo del creador y de lo creado, el poder de la palabra como dioshacedor y de la poeta como madre-corporeizadora a la vez que proyecta, con su palabra y sus indagaciones sobre la naturaleza de la expresión poética y de la existencia, su afirmación vital ante el mundo y la poesía así como su identidad femenina como ser gestante y creador. Cuatro obras representan el punto culminante de su orbe poético por: Configurado tiempo (1974), Invención de la luz (1978. Premio Carabela de Oro, 1977), Desde Chanatel, el canto (1981. Finalista del premio Ángaro), y Como quien no dice voz alguna al viento (1984).

La tercera etapa, fase de reproducción reconstitutiva en plenitud, supone un ahondamiento en temas que ocuparon su poesía anterior a la vez que emergen nuevos referentes, aunque en menor cantidad, fruto del paso del tiempo y de la madurez como persona y poeta. Pasan a ocupar lugares destacados temáticas como las de la memoria y los recuerdos como medios de alimentar el pasado que fue y configurar la identidad femenina que se es frente al no-ser; el deseo de acondicionar permanente la vida y su ser femenino creador por y a través de la palabra; elementos y referentes de la cotidianeidad y de la vida rutinaria y sosegada; y la trascendencia del ser creador y de la creación como vías de superación de algunos de los dramas del ser humano como el del paso del tiempo, el desaliento, la fragilidad de la existencia humana y la muerte. La poesía, la literatura, se erigen en legado y testamento vital perenne de la escritora, en claves que ahorman la infinitud del ser por la creación, frente al olvido y la muerte. Esta última fase comprende los libros Retornos sobre la siempre ausencia (1989), El sol, la sombra, en el instante (1994), Trasterrado marzo (1999), Palabras sobre los dias (2004) y Materia en olvido (2008).

\section{GEOGRAFÍA VITAL DE UNA POETA-ISLA ISLEÑA.}

Ana María Fagundo sufrió en su infancia las consecuencias de la guerra civil española. Dolor, incertidumbre, sufrimiento y muerte gravitaban alrededor de un tiempo amargo, entreverado por los silencios y el miedo de los mayores y unas vivencias contradictorias apresadas entre el peso de los dramas de la guerra y la inocencia y lucha de una niña canaria que siempre se mostró curiosa por descifrar todos los enigmas de la cosmogonía material y espiritual en la que se insertó su existencia en el contexto de Tenerife. En este tiempo de la niñez, adolescencia y juventud, su trayectoria vital estuvo siempre acompañada por la docta mano de su padre, pilar esencial en la formación primera de Fagundo, sobre quien extendió una magistral elegía plena de desgarro y dolor pero también de recuerdo, afecto y homenaje a la muerte de su padre, "amigo, padre, maestro" en Diario de una muerte, un libro que, en palabras de la autora, "nunca hubiera querido escribir".

La influencia de su padre, maestro nacional, terminó por decantar a la joven tinerfeña hacia los estudios financieros en la Escuela de Comercio de Santa Cruz donde obtuvo el título de Perito Mercantil en 1954 y el de profesora de Mercantil tres años más tarde. Sin embargo, la trayectoria profesional con la que Fagundo pretendía abrirse camino laboral experimentó un giro radical en 1958 tras la obtención de una beca Anne Simpson para estudiar en la Universidad de Redlands (California). En la institución académica americana permutó el orbe de los números por el de las letras al graduarse en literatura española e inglesa en 1962. 
Después de completar sus estudios en otras universidades norteamericanas como Illinois y Washington, se doctoró en esta última en 1967, siendo, de inmediato, reclamada en el campus universitario de Riverside (California) para formar parte de su claustro de profesores en la especialidad de literatura española.

Los exiguos datos apuntados revelan el profundo cambio experimentado en el círculo laboral previsto por Ana María Fagundo al renunciar a un proyecto central inicial en pos de una pasión vital arraigada y arracimada fuera de su zona de influencia insular y lejos del área mercantil en el que había fijado su ejercicio profesional. A partir de ese momento docencia, vida y creación se fundirán en un cronotropo alejado de lo que podría haber sido una existencia diametralmente diferente.

Sin embargo, la poeta canaria no pudo sustraerse a su pasado. Al contrario, la isla y su entorno, el recuerdo de los años insulares y el universo familiar y existencial vivido se trenzaron indisolublemente en su quehacer profesional, su historia postrera y su escritura. La singular sensibilidad y el recuerdo del tiempo en el archipiélago canario se aunaron en la práctica estética de Fagundo con el fin de proyectar su carácter insular sobre su vida real y poetizada hasta hacerlo uno de los núcleos compositivos más representativos y caracterizadores de su obra. En una entrevista concedida a Victoria Urbano la escritora canaria subrayaba que "la juventud, la niñez y el paisaje que la vio nacer y crecer estará siempre en el fondo de cualquier poeta lírica" (1984, p. 76). Un alma sensible como la de Fagundo no pudo sustraerse al impacto que la configuración geográfica de una isla como Tenerife ejerce en sus gentes y en ella misma, al contrario, en sus versos reivindicó su condición insular y el impacto que la geografía humana, natural y cultural del archipiélago canario ejerció siempre en su ser más profundo:

tengo la fortuna de haber nacido en una isla que se levanta en punta hacia el cielo y que se hunde infinitamente en las profundidades del mar. ¿No es este el más acabado símbolo de la condición del ser humano; solitaria isla entre dos inmensidades de azul: nacimiento y muerte, y en el centro, el ser pugnando por encontrar alguna clave de lo que es, de por qué se es? Y por si fuera poca la fortuna de nacer "isla en una isla". Nací y crecí además en un archipiélago ("islas en alborozado apiñamiento/ islas todas en una única isla"), interminable sucesión de seres que viven, son, se sienten, pero que, definitivamente, están dentro de sí mismos solos y... acompañados. [...] Mi paisaje canario es a la par que real, el símbolo perfecto de mi visión poética-existencial. Creo que hubiere vivido donde hubiere vivido, en mis islas o fuera de ellas, esa geografía estaría siempre en el fondo de mi estar poético. (Urbano, 1984, pp. 76-77)

Ana María Fagundo no pudo sustraerse a los mitologemas propios de los escritores insulares. Rasgos como los atributos psicogeográficos (el paisaje, la insularidad, la soledad, el aislamiento), la geometría del Teide, la vegetación y las particularidades de sus espacios naturales indómitos así como la siempre inquietante presencia y relación con el mar se convirtieron en referentes constantes de su paisanaje poético.

La ausencia de su isla natal, a la que regresó siempre que pudo, impregnó su poesía con una impronta personal inconfundible. Ella, poeta-isla independiente nacida en un espacio distintivo como Tenerife, convirtió la/su isla real o imaginaria en tema recurrente desde su primer libro, Brotes, en cuyas páginas se recogen poemas como "Tenerife", "Canarias" y "Azul-isla" donde el mar irrumpe como "un puño englobando/ el quehacer de mi retina" y se muestra, inexorablemente, abrazado a la tierra: "IIsla y mar en un abrazo de extática agonía!”; donde las islas se convierten en “¡Escalones de mis sueños, / islas todas en una única isla"; y donde emerge la nostalgia de un espacio insular que se hace más presente en la distancia: "No hay sueño bastante / para este dormitar inmenso / de cono erguido en la soledad. / Ni azul hay para este anhelar/ azul-celeste, / para este batir azul-ala / del quererse. / iQué dolor de azul en punta / sobre el alma!”1. (Fagundo, 2002b, vol I, pp. 96-97)

Aunque buena parte de su obra se puebla con simbología del paisaje canario rememorado, configurado por símbolos como el mar, las rocas, los cardones, el viento, la vegetación de la isla o sus volcanes, en un intento de hacer presente, casi tangible, el pasado, en Isla adentro, Configurado tiempo y Desde Chanatel el canto, se aúnan aún más el paisaje rememorado con el recogimiento y la soledad de la creadora en el momento presente y con el texto especular y territorial de su propio cuerpo de mujer. Emerge el cronotropo real y recordado habitado y la geografía albergada reflejada en el cuerpo del paisaje de su isla natal, Tenerife, hasta llegar a 
configurar un correlato temático específico y diferenciador en la poesía de Fagundo. Para Candelas Newton "la triada poesía-fisiología-geografía y sus derivados poema-cuerpo-isla" (1990, p. 22) constituyen algunos de los correlatos simbólicos esenciales sobre los que se sustenta una parte importante de la construcción epistemológica de Fagundo. En ellos brota un deseo de afirmación vital que, como en la geografía natal en punta de la isla tinerfeña, la hablante experimenta en su cuerpo y ser interno e intenta trasladar y configurar en el espacio poemático para afirmarse como ser femenino insular y para forjar una identidad poética que quiere abrirse camino desde el espacio de su cuerpo de mujer, desde su ser interior insular influenciado por el paisaje habitado y desde una concepción literaria individual donde el poema-cuerpo-isla se eleva como síntesis de conciencia y voluntad de ser donde es posible aunar la articulación de su identidad. En definitiva, "si el poema-materia equivale al texto de su cuerpo, este, al mismo tiempo, se ve reflejado o inscrito en el cuerpo paisaje de su isla natal" parar forjar uno de los más singulares símbolos del decir y del sentir fagundianos (Rolle, 1997, p. 24).

Además de en Isla adentro, a partir de Configurado tiempo el paisaje alcanza un plano simbólico y material esencial para su poesía. La isla, analogía de su ser y símbolo de su reflexión metapoética, emerge trascendida en sus poemas mediante la apropiación literaria del entorno físico y natural, el espacio geográfico de la infancia recobrada por la memoria, donde tanto palabra como poeta habitan y renacen y donde ambas logran una armonización clave para un ser ahora liberado, íntegro, pleno y consciente de su identidad ${ }^{2}$. Se produce una regeneración personal cuando, gracias a la triada poema-cuerpo-isla se recobra y se hace carne el pensamiento mediante la palabra y el redescubrimiento del cuerpo-isla de la escritura y, con ella, del ser y la identidad buscada por la poeta, como se expresa en poemas como "Isla", "Esperanza" y "Reverdecida" del que se reproducen sus versos finales:

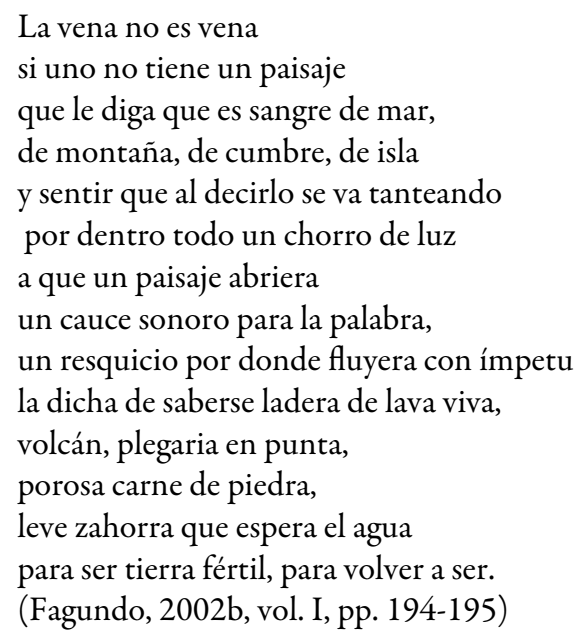

PASIón POR VIVIR, PASIÓN POR CREAR: ClAVES ESENCIALES DE SU POÉTICA

En la entrevista arriba citada, concedida en plena madurez creativa y personal, Ana María Fagundo subrayó que el mensaje poético subyacente a toda su poesía y, por tanto piedra angular de su doctrinario ideológico era el de la afirmación "de la vida pese al vacío". (Urbano, 1984, p. 77)

En su poética, Ana María Fagundo parte de una concepción vitalista y gozosa de la existencia a pesar de las incomprensiones, de los dolores y de las sombras de muerte, desamparo y desolación que siempre cohabitan en el ser humano desde diferentes perspectivas y en distintos momentos de su historia. Su impulso creador parte de un deseo de gestación o de configuración permanente de la vida ya sea la personal, la creadora o la creada. Desde el despertar de su vocación literaria, la poeta indaga en el siempre etéreo territorio del deseo de conocimiento aunque su búsqueda no aspira a dar cuenta de aquellos espacios recónditos, metafísicos, 
inefables o ininteligibles. Su indagación se dirige en pos de la iluminación del ser, de la vida, de la creación o del conocimiento de cuanto la rodea. Vida y creación, existencia y literatura, se funden en una ósmosis interactiva desde su primer poemario Brotes (1965). Como ella misma ha apostillado, en connotación próxima al pensamiento de Gloria Fuertes, la escritora canaria nació para poeta, para ser escritora y hacer de la escritora su sino vital. Su misión orgánica y animista no es otra que la de la escritura, la de la creación poética al afirmar que: "Mi relación con la poesía es el de un continuo enamoramiento de por vida" (Fagundo, 1985, p. 93). Esa y ninguna otra fue su esencia vital, la razón de su existencia como persona y poeta en esta dimensión llamada vida, su forma de estar en el mundo, de relacionarse con él y de encontrar su habitación propia; un espacio real pero también trascendido por la ficción literaria gestado por la poesía que se convirtió en territorio y cronotropo personal, único y originario: "Para mí la poesía es mi forma de estar instalada en esta dimensión que llamamos 'vida”" (Fagundo, 2006, p. 15).

Creación y vida tienen a la palabra, al logos, y al amor como correlatos esenciales en su proyección práctica mientras que su base se fundamenta desde una concepción particular e individualista del quehacer poético en la línea de poetas independientes y singulares aunque, en su ideario, se atisben vestigios adyacentes a las teorías poéticas rubendarianas. Si el poeta nicaragüense remarcó “mi literatura es mía en mí” en el prólogo a sus Prosas profanas con la intención de subrayar el carácter personal y diferenciador de su sistema doctrinal modernista, Ana María Fagundo titula uno de sus textos más sustanciales en cuanto a la reflexión poética con ese mismo encabezamiento "Mi literatura es mía en mí" en clara alusión y defensa de la autenticidad, de la particularidad y la personalidad propia e individualista de su práctica creativa.

Desde los textos iniciales de Brotes hasta sus últimas composiciones, su poesía indaga sobre el eje central de la palabra y de la creación al estimarse como matriz de todo cuanto atañe a la génesis de lo material, de lo espiritual y de lo existencial, es decir, la palabra es fuente primera y última de creación. Para ello, elaboró un universo simbólico particular construido sobre la base de referentes femeninos biologicistas (cuerpo, cordón umbilical, sangre, alimento, respiración, maternidad, útero, parto...) y fundamentos de base feminista (inscripción del cuerpo femenino en el texto, simbolismo y materialización del ser femenino como eje transmisor de la vida y de la palabra, primacía del orden simbólico de la madre) como ejemplarmente se expresa en "Poema de cumpleaños" de Configurado Tiempo:

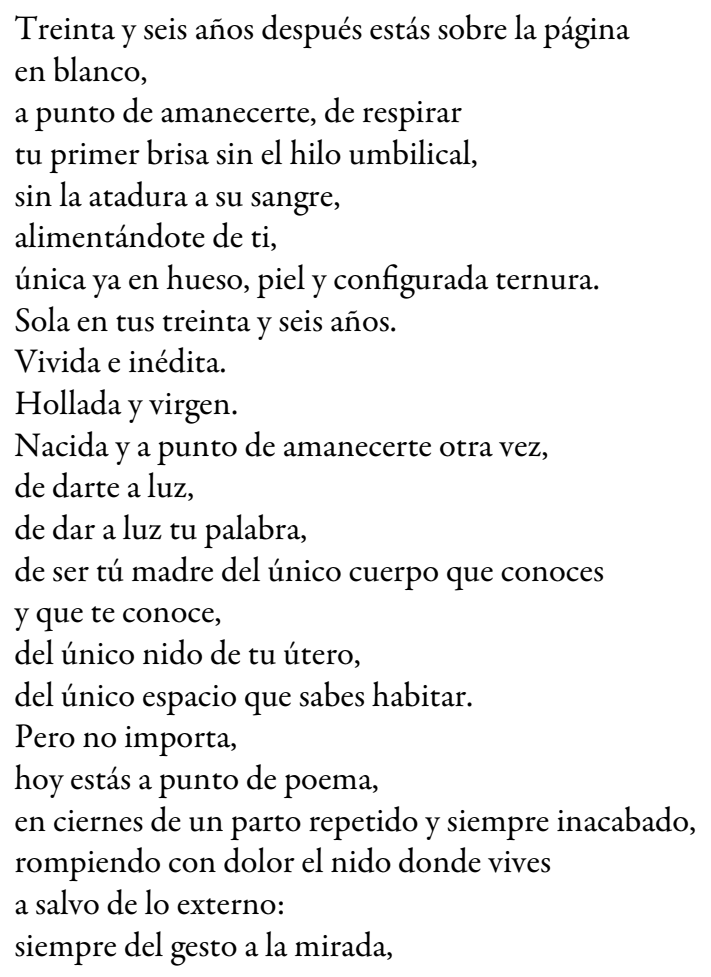


del amor al amor siempre.

Treinta y seis años amaneciendo.

(Fagundo, 2002b, vol. I, p. 223)

Indagaciones sobre la palabra, la creación o el poema en relación con la biología femenina son constantes referentes en toda la trayectoria poética de Ana María Fagundo. La palabra y la poesía habitan en el ser humano que es Fagundo formando parte de su propia biología esencial. La poeta ha nacido para crear vida por medio de la palabra, para gestar seres vivos que no son otros que los poemas, para ser madre-poeta portadora y dadora de vida en el proceso de la gestación y del parto del verso aunque, en contraste con los nacimientos biológicos, la generación y el alumbramiento artístico implique un movimiento eternamente inconcluso, un permanente hacerse y deshacerse, un constante oleaje de ser frente a no-ser siempre en ciernes e incesantemente inacabado "hoy estás a punto de poema, / en ciernes de un parto repetido y siempre inacabado".

La concepción lírica de la poeta canaria asume que la palabra se erige en ser-origen y fin-permanencia de todo. Por encima del sujeto y del tiempo, la voz de la madre-poeta hecha carne en la grafía es lo que sobrevive, lo que siempre está, lo que queda, según se segrega en muchos de sus textos y se puede apreciar en el poema "Permanencia de la palabra" texto que cierra la sección "Palabra" de Como quien no dice voz alguna al viento. Ella, la palabra, es la configuradora del mundo no solo por su capacidad para dar forma corpórea a la idea sino porque solo en sus dominios es desde donde se alcanza a expresar el pensamiento de su alma poética, gestadora y maternal.

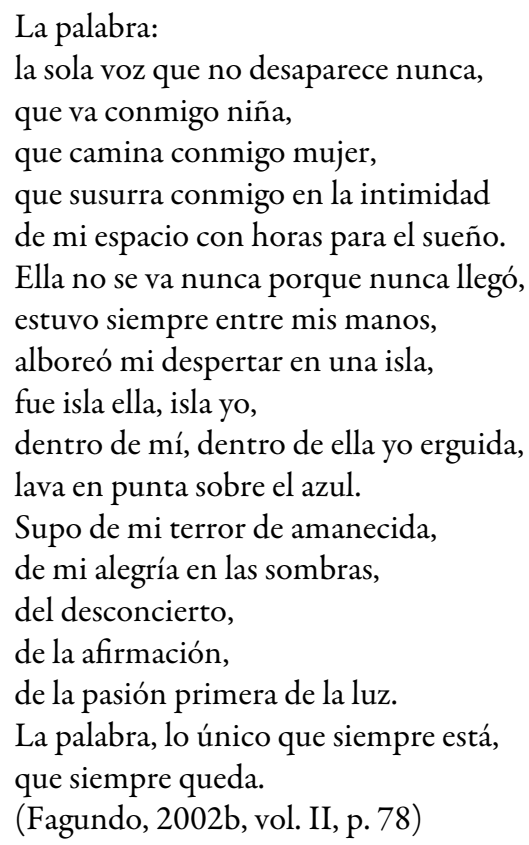

Lo innombrado es lo ignorado, lo inexistente, lo intangible, por lo que, para una poeta cuya base filosófica parte de la consideración de la poesía como vehículo de conocimiento, la herramienta cognoscitiva que le permite explicar(se) y conocer(se) no es otra que la palabra. Desde sus primeros poemas, la correspondencia entre la poeta y el/su mundo pasa siempre por la mediación de la palabra. Ella es voz que nombra la inmaterial realidad en ciernes, es onda gráfica que corporiza el mundo interior y forma que se exhibe como signo determinante de todas las representaciones materiales y/o simbólicas. En Retornos sobre la siempre ausencia la palabra se exhibe como algo sacralizado, un numen sagrado invocado: es el signo que marca el camino, el reflujo marino que oscila cual oleaje o vaivén entre el decir y el no-decir hasta las arenas de la playa, del poema; emerge como algo esencial intemporal dando voz, aliento, forma al cuerpo lírico ya dolido ya alborozado "retornando siempre como un dios / a tu página en blanco" (Fagundo, 2002b, vol. II, p. 112) para configurar 
un universo donde la palabra se alza como deidad capaz de superar las distancias que separan el mundo de las ideas de su sustanciación poética esencial: el texto en particular o su obra en general si se atiende al poema "Oración por la palabra" donde se condesa a la vez que se explicita cómo la palabra ha marcado el curso del ser como persona y del alma como poeta de Fagundo al enunciarse y compendiarse en los primeros versos del poema "Oración de la palabra" lo que la palabra había implicado en su devenir histórico y creativo puesto que cada uno de sus versos se relaciona con el título de los libros publicados hasta ese momento:

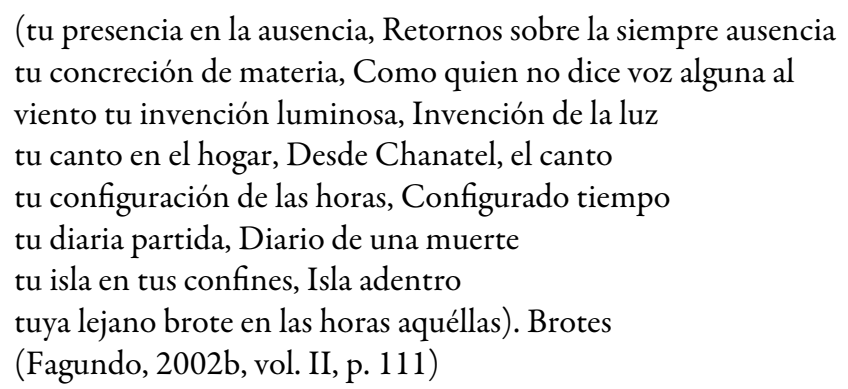

En Como quien no dice voz alguna al viento, la palabra es reclamada en su texto liminar "Indagación”, es convocada en su apertura "Llamamiento a la palabra" y es exorcizada en su final "Conjuración de la palabra". Desde su raíz, toda la obra supone una búsqueda de afirmación e identidad ontológicas cuyo epicentro es el lenguaje en cuyos signos se encierra el ser y su configuración. El libro y buena parte de su poesía implica un deseo de penetración e indagación en la palabra en tanto en cuanto naturaleza creadora y signo de expresión del pensamiento y del ser. En ella se encierra la esencia de la existencia y su configuración innata por ser el instrumento de conocimiento del mundo y de (re)conocimiento del ser humano en él. Cuando la palabra se escribe se materializa y, con ella, la poeta es/emerge por el lenguaje. Por el contrario, si la palabra no se articula, la hechura se desmorona y el vacío, la ausencia y la distancia se imponen, o lo que es igual, prevalece el hueco del no ser, tal y como revela el poema "Fluir":

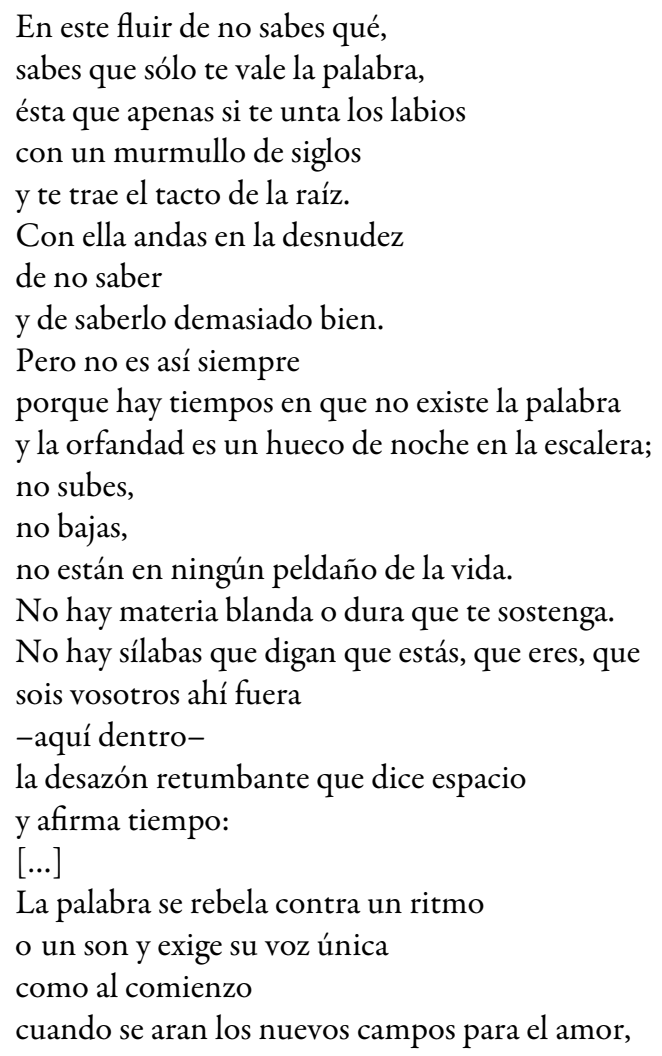




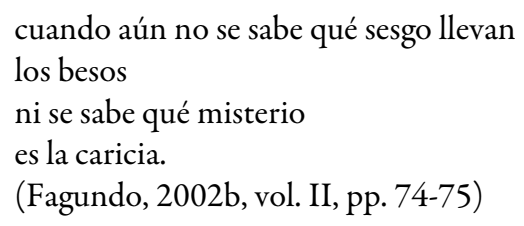

La palabra alcanza un amplio muestrario de funciones, significación y valores figurativos en la poesía de Fagundo. No obstante, a tenor de lo explicitado arriba, el valor y las direcciones de la palabra poética, sustento esencial de la lírica de Fagundo, podrían sintetizarse en tres órbitas siguiendo a Silvia Rolle (1998, p. 749). Para ella, el origen de la palabra, como el del ser humano está en el cuerpo femenino, y es en femenino que concibe al verbo poético. La palabra es forma creada, es vida en su corporeización por el lenguaje siendo las poetas, como dadoras de vida biológica y literaria, las que mejor pueden plasmar el acto de la creación al ser un acto de alumbramiento. Por otro lado, "la autora presenta la palabra como referente especular del yo". La palabra es el medio desde el que se articula todo su pensamiento y se erige en vehículo de conocimiento. La palabra, por tanto, es instrumento fundamental para pensarse, mostrarse, sentir y explicitar el conjunto de sus ideas así como de sentirse ser y proyectarse en el mundo por la poesía. En la poeta "habita, se refleja, se articula y se perpetúa”. La palabra es medio de superación de cualquier barrera espacial y temporal por su capacidad de permanencia y trascendencia. En última instancia, "la poeta es poseedora de palabra y es poseída por ella, con cuya luz se lanza a configurar, a ponerle hechura y a preservar el mundo". Gracias a la palabra, la poeta "va tejiendo la vida, ordenando su cauce, vertigineando al tiempo, siempre en pos de negar la destrucción, de llenar la ausencia" como atestigua el poema "Curso de mi palabra" de la sección "Finale" de Trasterrado Marzo:

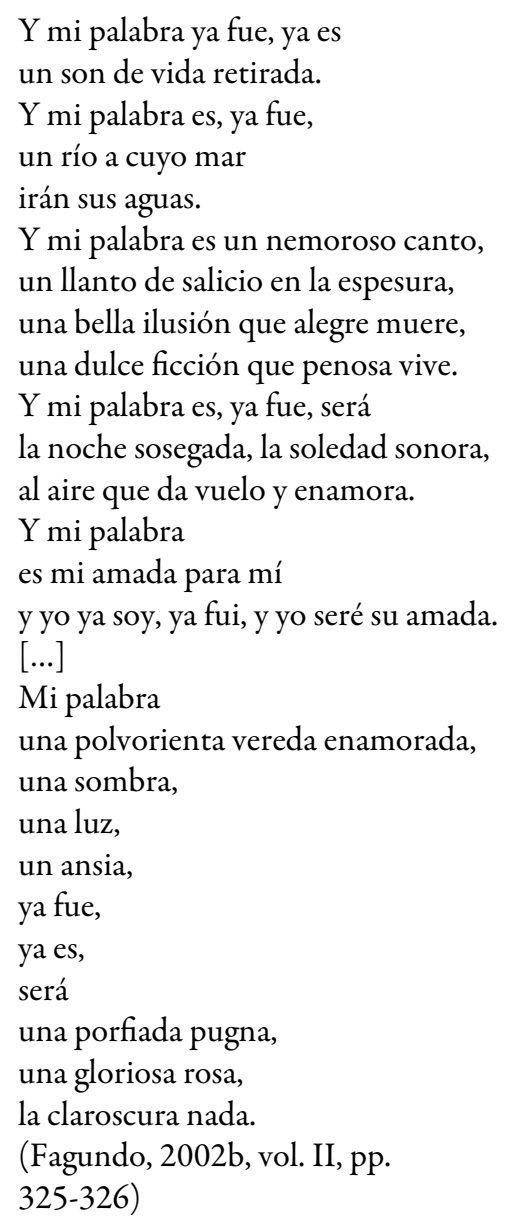


Junto a la palabra, la segunda de las claves de bóveda de la poética fagundiana es la reafirmación de su pasión por la vida. Su literatura implica una defensa de lo vital frente a las sombras, el incesante paso del tiempo, los pliegues del dolor y de la muerte en sus dimensiones autobiográficas y colectivas y de los problemas de la civilización contemporánea aunque todos estos temas estén muy presentes en su obra como antítesis o contrafuertes indisolubles de la propia vida. En sus versos, a pesar de constantes temáticas siempre perturbadoras y de aliento negativo (recuérdense poemas como "En Londres en primavera yo espero a que las mujeres" de Desde Chanatel, el canto sobre el aborto; o "Cohetes (11-9-01)", "Torresgemelas", "Aliados y desaliados", "Los hombres", "Guerra", "La guerra no ha terminado" de Palabras sobre los días sobre el terrorismo), la poeta ha logrado entonar un canto de amor a la existencia a través de su conjunción con dos ejes referenciales cardinales de su práctica estética: el del amor y el de la luz que se proyectan como claves iluminadoras y de afirmación vital frente a cualquier inquietud o desasosiego existencial porque como incluso llega a cantar en su último libro Materia en olvido: "La vida es./ La vida sigue" (Fagundo, 2008, p. 40).

Existencia y literatura se fusionan y entrelazan para convertirse en vehículos conformadores de vida, de esperanza y de futuro frente a los signos de la angustia y de la pesadumbre focalizados en asuntos como los de la (in)finitud del ser, el del dolor y la soledad del ser humano o la acechante idea de la muerte, del paso del tiempo, de la nada y del vacío existencial. La poesía como la vida son actos de amor, de gestación de luz, de vivencias y experiencias cíclicas creadas para seguir siendo, para seguir viviendo y afirmando al ser humano frente a su finitud o cualquier tipo de desazón. La vida, como el amor y la palabra, irrumpen como refugios o como embriones de una existencia que debe alzarse por encima de todo al estimarse como esencia misma de un todo orgánico y armónico, de un panteísmo universal. En muchos de los poemas de Invención de la luz se pueden apreciar estas ideas pero especialmente significativo es el poema "Amor" donde la hablante sostiene:

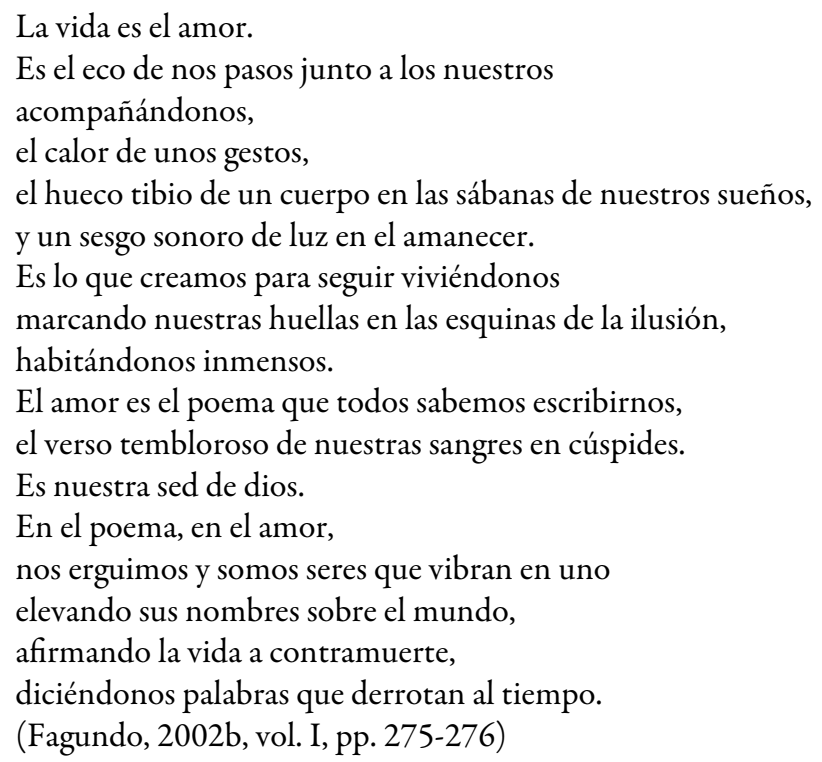

Igual de revelador y significativo es el poema "Nuestro cuerpo" conformado sobre la base de antítesis cimentadas en torno al cuerpo como raíz del amor y del dolor aunque, en plena dialéctica de contrarios (glorioso cuerpo/ pobre cuerpo; iluminado/ desolado cuerpo; tránsito/perennidad; ilusión/tristeza, caída/ erguimiento), siempre se alce la vida, la perpetuidad de la especie, el amor universal de la creación y de lo creado, transitorios por su carácter cíclico pero perennes en sus sucesivas generaciones y permanencias:

[...] Nuestro ilusionado cuerpo,

nuestro triste cuerpo dolido que admite su Džágil hueso, su débil ternura, su precaria simiente, 


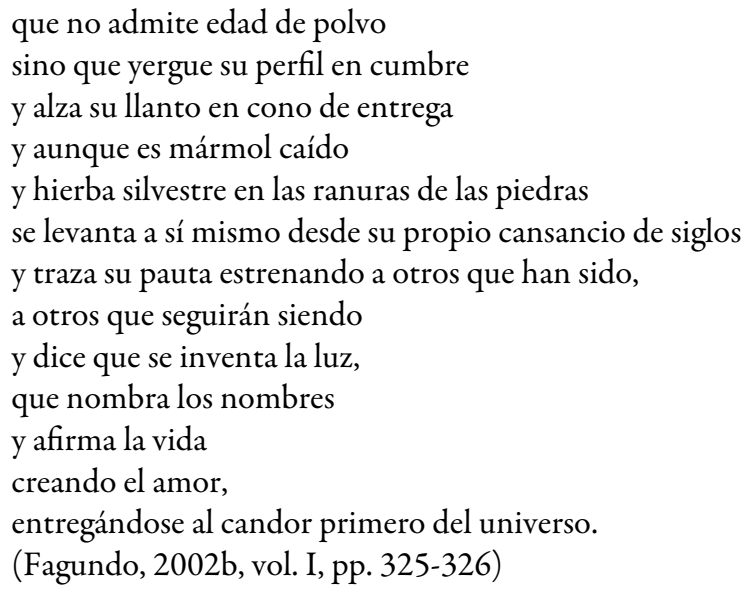

\section{Desde Chanatel, el Canto, la Creación absoluta}

Poeta trasterrada, como ella misma se calificaba, es en la lejanía donde mejor se apodera de la isla y de su ser biológico y creador, con una visión particular que la hace fundirse en ella, en el ser mujer-isla que nace y se hace por medio de la escritura porque sabe que volver a la isla, al cuerpo natal, a la geografía primera, es volver al ser, a la esencia, a la identidad y a la creación cuya máxima expresión se alcanza en la invención de "Chanatel", donde la isla física y material se trasciende con la invención de un nuevo espacio geográfico imaginario: Chanatel, donde halla las respuestas antes inaccesibles.

Con este poemario, Ana María Fagundo consigue desvelar y superar muchas de las incógnitas ontológicas, intelectuales y cognoscitivas que habían ocupado su producción anterior a la vez que da vida a un cronotopo personal y temático con el que logra trascender muchos de los miedos, de las incomprensiones y de las contrariedades que la habían acuciado.

Como expresa el poema "Te estrenas desde mi canto de tiempo, Chanatel”, Chanatel supera una dialéctica siempre inquietante como la de la finitud de la vida porque Chanatel se configura como territorio y período imperecedero. Es vida fuera del tiempo y del espacio por lo que se supera la brecha de la muerte. Es el desvelamiento de la eternidad por la aprehensión del pasado a la vez que descubrimiento de una vida propia gestada por ella misma en el acto creativo intemporal e inespacial sin "infancia ni horizontes misteriosos por descubrir". Chanatel es el diálogo con uno mismo, con el universo, con la creación para desentrañar muchos de los misterios que cercaban a la poeta y que ahora consigue razonar al hallar explicación a muchos de los porqués que la inquietaban y a las incomprensiones pretéritas:

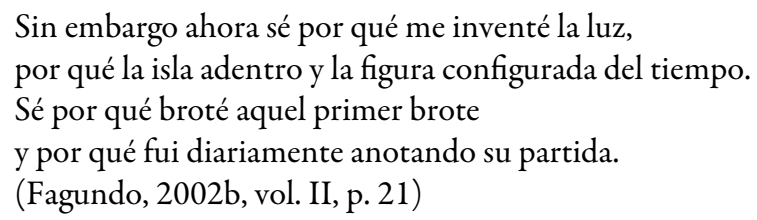

Como llevará a cabo hasta sus últimas composiciones, en meridiana alusión a las causas de la creación de sus libros, la poeta isleña ha llegado a comprender y a conocer la causa de aquellos distantes desvelos y las respuestas a los interrogantes que la (pre)ocupaban. La vida, como la creación es un latente hacer(se), un perenne volver y retornar, un sempiterno (re)vivir. Chanatel es vida: "vida desde dentro. Vida desde este soñar despierta/ en mi isla de siempre" (Fagundo, 2002b, vol. II, p. 20). Aunque la vida, como el tiempo, no pueden detenerse en su fugacidad ni siquiera en Chanatel, se descubre que el paisaje de la escritura no tiene infancia, ni finitud, ni horizontes misteriosos que descubrir porque, en su organicidad, es capaz de superar el fluir temporal. 
Chanatel es canto, es alivio placentero, es alegría y amanecer, "Amanece y es un canto" se titula uno de sus poemas. En el espacio de la escritura se inventa o se configura la vida a veces tan real como la existencia pero, más allá de esto, se descubre que el poema emanado desde el cuerpo-isla de la poeta trasciende el horizonte espacio-temporal y su efecto anulador sobre el paisaje físico y el ser finito de la autora. Es el descubrimiento de la auténtica vida, la del interior, la que ha habitado el ser y en el cuerpo de la poeta y ahora alcanza a desenmascarar en el acto creativo aunque aún no se tengan palabras con las que revelarlo. No obstante se tiene conciencia de que esas palabras y esos mundos habitan su interior y tarde o temprano brotarán en el poema. Es vida desde dentro hacia fuera: "Vida desde este soñar despierta en mi isla de siempre" y es luz perpetua: "La luz desde Chanatel se tiene siempre entera: / todo el amor / todo el dolor, / para que la vida siga dibujando su ilusoria silueta" (Fagundo, 2002b, vol. II, p. 25). Chanatel hace surgir el ser perdido de la escritora difuminado en el tiempo sin isla. Chanatel inventa y forja una nueva vida al convertirse por la poesía, por el cuerpo-isla de su creadora, en engendradora de vida continuadora de una genealogía femenina cíclica. Es el espacio infinito e inextinguible desde donde se ilumina la oscuridad pasada y encuentran explicación los misterios insondables del ayer y las incomprensiones sobre las acotaciones espaciales e imposiciones antiguas ${ }^{3}$.

Chanatel es una afirmación de vida frente al vacío, una fuente inextinguible de vida. A pesar de que la segunda parte del libro, la titulada "Duendes", está marcada por la crítica a la civilización actual ocupando un lugar central una crítica al aborto, a las guerras y a los sistemas políticos y económicos del fin del siglo $\mathrm{XX}$ en poemas como "En Londres en primavera yo espero a que las mujeres", "En Londres los hijos de óvulo y semen" o "Yo he visto niños salir de las cloacas de Estambul", en su final vuelve a hacerse patente que el libro es un clamor existencial, un grito poético por la luz, por la palabra, por el poder y querer vivir, que nos revela un alma ardorosa que logra hacer de la literatura lo que ésta debe ser: profecía y testimonio de una poeta que apostó por la autenticidad de la poesía al engendrarse y alumbrarse de una verdadera autenticidad vivencial como emanación del ser creado y creador. Desde Chanatel, el canto; desde Chanatel, la creación; desde Chanatel, la vida:

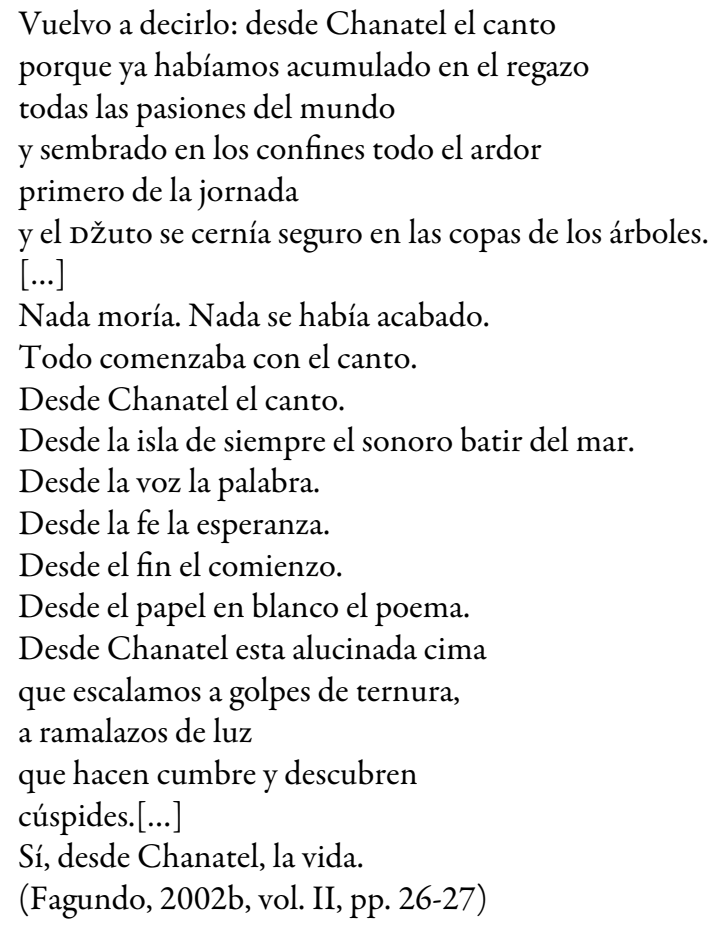

Chanatel configura una propuesta de vida, de afirmación y de perennidad por la escritura. Simboliza un punto de encuentro entre el pasado y el presente a la vez que implica una superación de cualquier marco espacio-temporal porque la vida, como la creación y la existencia, es un eterno retorno, un "yéndonos y 
quedándonos" sempiterno, un continuo fluir. En él, "el ser / ha ido dejando su impronta de vida / diciendo que cantó dolor, / que rio desaliento, / que durmió ensueños" aunque es conocedor de que "nada de lo que hizo, / nada de lo que seguirá haciendo / tiene punto de comienzo ni final / ni trayecto a recorrer". Chanatel es canto de pirámide erguida pero también de laberinto profundo donde la muerte es vida "islas erguidas pugnando por serse eternamente" (Fagundo, 2002b, vol. II, p. 64).

En definitiva, palabra y vida, creación y existencia, ficción y realidad se entrelazan indisolublemente en una obra poética singular como la de Ana María Fagundo, poeta-isla que hizo de la literatura su pasión de vida y de la creación su motor existencial para construir un universo lírico propio que tiene en Desde Chanatel, el canto uno de sus paradigmas claves desde el que sondear una poética autóctona que pretendió siempre afirmar la vida, defender la poesía como vía de conocimiento y superación de angustias por la palabra y el amor y hacer de la poesía territorio personal desde el que ser(se). ${ }^{4}$

\section{REFERENCIAS}

Fagundo, A. Ma. (2002a). Mi literatura es mía en mí. En G. Paolini (ed.), La chispa' '85. Selectec Proceedings (pp. 83-92). New Orleans: Tulane U.

Fagundo, A. Ma. (2002b): Obra poética (1965-2002). 2 vols. M. Álvarez ed. Madrid: Fundamentos.

Fagundo, A. Ma. (2006): Poética y antología personal. Salina. Revista de Lettres, 20, 15-36.

Newton, C. (1990). Introducción. La poesía de Ana María Fagundo. (Poniéndole hechura al ser por la palabra). En A. $\mathrm{M}^{2}$. Fagundo, Obra poética 1965-1990. Madrid: Endymión.

Rolle, S. (1997): La obra de Ana Maria Fagundo: Una poética femenino-feminista. Madrid: Fundamentos.

Rolle, S. (1998): La restitución de lo femenino en el discurso poético de Ana María Fagundo. En Actas del XIII Congreso de la Asociación Internacional de Hispanistas (pp. 749-759). Madrid: Castalia.

Rolle-Rissetto, S. (1999): La iluminación de lo inefable mediante la palabra poética: A. Ma . Fagundo, canaria universal. En Ana María Fagundo, Antología Poética. Emilio Coco (ed.) (pp. 7-29). Bari: Levante Editori.

Sauter, S. (1994): Entre Eros y Logos en la poesía de Ana María Fagundo. Letras Femeninas. Número Extraordinario Conmemorativo 1974-1994, 57-69.

Urbano, V. (1984): Entrevista a Ana María Fagundo. Letras Femeninas 10 (2), 74-81.

\section{Notas}

1 Las citas, salvo las correspondientes a los dos últimos poemarios de la poeta, se toman de la edición Ana María Fagundo, Obra poética (1965-200) de, 2 vols., editada por Myriam Álvarez, recogida en la bibliografía.

2 "[...] y ya no eres isla prisionera / en una jaula azul de aire y agua / sino que jubilosamente madura / te desgajas en palabras / que irrumpen gozosas y te dejan / limpia, recién estrenada, / dura y al mismo tiempo frágil. / Entonces te liberas de tu destino de isla / te alzas más allá de la sangre, / de la piel, de los músculos / y así crecida te levantas sobre ti misma / afirmando tu derecho de ser tierra vertical / que aspira a la permanencia / aunque se sepa sujeta a la mar / y coronada por una falsa bóveda de aire azul” (Fagundo, 2002b, vol. I, p. 203).

3 "Cuando acotaron un espacio para mí / poniéndole ventanas, suelos, techos, paredes, / yo le di nombre un domingo luminoso de mayo / (pensador, platera, mon cheri, tomorrow, / trigos para el comienzo / sueño de hogar perdido, recobrado). / He ido poniendo horas de cerámicas y libros, de maderas y olor a cocina, he ido poniéndole poemas al sesgo de cada día. / Este espacio mío ahora, mi nicho en vivo, estará acotando el aire aquí cuando yo sea / terrón de tierra, guano fértil en alguna cuneta / [...] y habrá nuevos nombres que dar a los espacios, / risas nuevas, pasos nuevos, / Nuevos amores entre estas paredes mías hoy, / mías mientras diga «vivo» y sea inercia de movimiento / y garabatee palabras que el viento se lleva / sobre el papel iluso de mis sueños" (Fagundo, 2002b, vol. II, pp. 25-26).

4 Este ensayo está vinculado al Proyecto de Investigación «Poéticas de la transición», Referencia FFl2013-41321, del Ministerio de Economía y Competitividad. 